Transliteration as a bridge to learning for bilingual children

Salman Al-Azami, Department of English, Liverpool Hope University

Charmian Kenner, Mahera Ruby and Eve Gregory, Department of Educational

Studies, Goldsmiths, University of London

This is an electronic version of an article published in:

International Journal of Bilingual Education and Bilingualism 13 (6), 683-700

The IJBEB is available online at:

http://www.informaworld.com/smpp/content $\sim \mathrm{db}=\mathrm{all} \sim$ content $=\mathrm{a} 919408037 \sim \mathrm{frm}=$ titlel

$\underline{\text { ink }}$

\begin{abstract}
This paper examines how transliteration can be used as a bridge to learning for children who are studying more than one script. The focus is on second and third generation British Bangladeshi children aged seven to eleven, attending London primary schools and learning to write in Bengali at community-run after-school classes. An action research project explored how Bengali could be used as well as English to enhance learning at mainstream school. Transliteration of Bengali into Roman script was found to aid this process in the following ways: as a communicative bridge between children, parents and teachers; as a conceptual bridge, promoting reflection on meanings and metalinguistic awareness; as a bridge to the Bengali script itself, mediating between oral and written representation; and as a bridge to new learner identities, enabling expression of ideas and building children's confidence as bilingual writers.
\end{abstract}

Keywords: bilingual education, biliteracy, metalinguistic knowledge, cultural identity, Bengali, Britain

\title{
Introduction
}

Transliteration is often used as a practical strategy in contexts where the written form of a language is unfamiliar or does not otherwise exist. For example, all the major religious scriptures in the world have transliterated versions along with their translations, to enable religious devotees who are unfamiliar with the language to read the text. Transliteration can also be found in literary works, to incorporate culturally significant words from other languages (Onwuemene, 1999). Most of the research on transliteration has been on the problems of transliterating one script into another; for example, on how to represent Chinese characters and the tonal features of Chinese languages in alphabetic script (Lau and Wang, 1993). Research has not focused on the area considered in this paper, of transliteration as a resource for learning.

In the action research study discussed here, which investigated how second and third generation British Bangladeshi children could use Bengali as well as English for learning in school, transliteration was initially employed out of sheer necessity since children were unconfident in Bengali script. When Roman script was used to represent Bengali, they were able to engage with texts in Standard Bengali and produce their own writing in Sylheti, a language closely related to Bengali that no longer has a written form. Parents and children could create and discuss texts at home, 
and primary school teachers who did not know Bengali could work with children on these texts at school. As part of the research, we therefore came to analyse how transliteration mediated learning.

This paper presents examples from bilingual activities carried out by a group of seven-year-olds with their parents and their primary school teacher, based around a folk tale, 'The Lion and the Mouse'. The data shows how transliteration fostered communication between children, parents and teachers during the learning process. Being able to access a written form of Sylheti or Standard Bengali acted as a catalyst for thinking and reflection, enabling children to deepen their understanding of meanings and enhance their existing metalinguistic awareness.

There are potential concerns as to whether transliteration could lead children to avoid the challenge of learning the Bengali script itself. The research found, rather, that writing in transliteration helped children work out how to represent sounds in Bengali script. In addition, children reacted positively to the use of transliteration since it enabled them to demonstrate and draw on their bilingual knowledge, thus broadening the scope of their identities as learners.

\section{A note on Bengali and Sylheti}

The majority of Bangladeshis in the UK originate from the north-eastern region of Bangladesh known as Sylhet. According to Chalmers (1996), the Sylheti dialect is rich and distinctive and reflects a number of influences, including Assamese, Arabic, Turkish, Nagri and Parsi. Sylheti used to have its own script known as Nagri, which dated back to the first decade of the fourteenth century and was derived from Bengali, Arabic, Kaithi, and Devanagari (Islam, 2003). Muslim writers of the Sylhet region especially used this script when writing on religion, since this involved many words from Arabic and Persian. However, the script became gradually extinct and Bengali became the only script in the region. Sylheti continued as an oral language only. The Sylheti speaking children in our study were in any case more familiar with Roman script than Bengali script, so transliterating Sylheti into Roman script enabled them to convert their speech into writing, as well as facilitating discussions with their primary school teachers who could then access the language of the children while doing bilingual tasks together.

Standard Bengali and Sylheti are closely related varieties. In the Tower Hamlets speech community in East London, where this study took place, it is common to switch between the two, so 'Bangla' is used as an umbrella term for these and other varieties. We have therefore adopted this term in our discussion below wherever children and parents would have been switching between different varieties. We have specifically distinguished between Sylheti and Standard Bengali where appropriate and necessary.

\section{Breaking the script barrier}

In multilingual contexts, transliteration is used for economic or educational purposes where participants do not share the same script. This is shown by two examples from 
Tower Hamlets itself. Firstly, in Whitechapel Market, a few blocks from the primary school that features in this paper, DVDs of popular Bollywood films are for sale with Hindi or Urdu titles printed in Roman script. These mostly originate from India, where there are a number of different languages and scripts, and it cannot be assumed that potential buyers of a DVD are necessarily familiar with any particular one. In order to promote sales, it is therefore necessary to transliterate the film titles into a widely known script, that of English. This feature is also very useful in Tower Hamlets, where although the British Bangladeshi children involved in the research would partly understand the spoken language in the films, they would not be able to read Hindi or Urdu script.

Secondly, a multilingual picture dictionary has been produced for use in Tower Hamlets schools. As it happens, the author is the brother-in-law of one of the teaching assistants in the primary school that participated in the research. Each picture in the dictionary is surrounded by four different versions of the word it illustrates: in Standard Bengali script, transliterated Standard Bengali, transliterated Sylheti, and English. The dictionary thus addresses the linguistic complexity of Tower Hamlets by enabling translation between Bengali or Sylheti and English, and providing access for those who cannot read the Bengali script. Originally, the latter category would have centred on non-Bengali speaking teachers in mainstream school, but increasingly it includes second and third generation children themselves, and even their parents.

How has Bengali script come to appear as a barrier to understanding in a locality such as Tower Hamlets, where Sylheti is widely spoken, other varieties of Bengali are also used, families watch satellite TV in Sylheti and Standard Bengali, and newspapers in Standard Bengali are available in most newsagents? The answer lies mainly in lack of access to educational facilities for studying Bengali language and literacy.

In the mid-1980s, a UK government enquiry on ethnic minority underachievement entitled 'Education for All', more commonly known as the Swann Report (DES, 1985), stated categorically that mother tongue teaching was not the responsibility of the state, and should take place outside school hours in sessions run by ethnic minority communities themselves. Despite evidence from research taking place at the time, such as the Mother Tongue and English Teaching (MOTET) project in Bradford, Northern England (Fitzpatrick, 1987), showing the positive effects of bilingualism on learning, this recommendation was generally followed by local authorities.

Thus although Bangladeshi-origin children were one of the groups identified by the Swann Report as seriously underachieving, they were effectively denied the possibility of developing their bilingualism through mainstream schooling. Ethnic minority communities still continue to run after-school or weekend language classes around the country, and hundreds of these are listed on the database of the National Resource Centre for Supplementary Education (www.continyou.org.uk), but mother tongue teachers are working against the odds with little access to training or resources, and pupils are only able to attend for a few hours a week. Tower Hamlets is one of the local authorities that financially supports such classes, and the borough's own statistics show that children who attend mother tongue provision do better in mainstream learning than those who do not (Tower Hamlets Community Languages Service, 2006). However, only a relatively small percentage of Bangladeshi-origin 
children attend the classes, presumably due to competing demands on their time and the lack of value attached by the wider society to bilingualism in minority languages. Despite the considerable efforts made by Bangladeshi parents who are determined that their children should learn their mother tongue, as shown by research in Tower Hamlets by Gregory and Williams (2000) and in Birmingham by Blackledge (2000), these challenges prove too difficult for many families to overcome.

A diminishing knowledge of Bengali script is therefore one of the consequences of the 'monolingualising' ideology (Heller, 1995: 374; Blackledge, 2004; Conteh et al, 2007) generally adopted by UK politicians and policymakers. Such an ideology also affects mainstream teachers' perceptions of what is possible in terms of using different scripts for learning in school. Although curriculum guidance documents in England now acknowledge the benefits of bilingualism and contain positive statements such as 'children's experience of different scripts at home should be acknowledged and built on when learning about the conventions of English' (QCA, 2000: 47), teachers still receive little or no training on how to work with a variety of languages and literacies in the classroom (TDA, 2008). Teachers in Tower Hamlets told us at the beginning of the action research project that they were uncertain of how to incorporate Bengali into classroom activities because they were unfamiliar with the language and the script. Whilst the National Languages Strategy for England (DfES, 2002) and European policies (Council of Europe, 1992; Beacco and Byram, 2003) officially encourage plurilingualism and the teaching of minority languages in schools, monolingual attitudes amongst some educators and in the wider society tend to prevail. Anderson et al (2008: 193) argue that 'the struggle between these contradictory perspectives results in 'incoherent discourses' around multilingualism' in the English education system.

This situation has several negative effects for Bangladeshi-origin children growing up in Tower Hamlets. Firstly, when children lose understanding of their mother tongue, whether spoken or written, this affects intergenerational relationships with parents and grandparents (Li Wei, 1994; Jessel et al, 2004) since language mediates shared experience. Secondly, reading literature and a range of other genres deepens understanding of a language and gives access to a wealth of cultural knowledge (Baker, 2006: 328), and children will be denied this opportunity. This is particularly the case when, as in Tower Hamlets, written texts are only available in the standard language, whereas other varieties dominate in spoken interaction. Finally, convincing arguments have been made for the key part played by literacy in the long-term maintenance of a minority language (Fishman, 1991). A study by Eilers, Pearson and Cobo-Lewis (2006) adds support to this thesis; second and third generation Latinoorigin children in Miami were found to be losing their Spanish competence unless they are schooled in Spanish, despite living in a community where spoken Spanish is regularly used in the business and social infrastructure.

What can transliteration offer in these circumstances? Transliteration is not in itself an answer to the perceived script barrier. Romanised transliteration cannot provide a completely accurate representation of Bengali, and cannot become a substitute for learning the script itself. However, this paper will go on to show that transliteration can open a pathway of communication between children, parents and teachers, thus fostering learning and feeding back into knowledge of Bengali script. 


\section{Literacy as an aid to learning}

Written expression of ideas gives the opportunity for further reflection and therefore acts as a basis for new learning. Vygotsky (1978) pointed out that writing involves 'second order symbolism', through signs that function as designations for spoken communication. He saw writing as an essential step forward in the ability of a child (and a society) to move from concrete 'spontaneous' concepts to more abstract 'scientific' concepts. Whilst there has been considerable debate as to whether oral cultures are less developed than literate ones (Goody and Watt, 1968; Ong, 1982; Street, 1984), writing may be seen to have advantages for particular learning purposes. Olson (1977) claims that writing enables people to free their minds from the demands of memorisation, releasing energy for conceptual thinking, and particularly for logical reflection on abstract ideas. In a similar vein, Ong (1982: 151) calls writing 'a consciousness-raising activity'. These arguments demonstrate the potential value of written language in promoting learning, both in terms of thinking about meaning and thinking about linguistic structure.

When writing takes place in a bilingual context, additional benefits can accrue. The process of translation can lead to in-depth consideration of different possible meanings for words and phrases on the page or screen. For example, Robertson (2002) describes how five-year-olds attending a lunchtime Urdu club at a UK primary school discussed English equivalents for Urdu words written on the board by their teacher. Moore (2002) shows how children and their teacher in an Italian/French bilingual classroom clarified the difference between 'grano' in Italian (grains of rice and wheat) and 'graine' in French (seeds, which corresponds more closely to 'seme' in Italian). Seeing more than one written language alongside each other also facilitates comparison between linguistic structures. For example, Edwards et al (2000) and Sneddon (2008) show how reading and writing dual-language stories stimulates metalinguistic awareness.

Finally, writing facilitates children's self-expression and sense of identity as learners; 'literacy is a key site for identity work' and literacy practices 'provide an arena for constructing and performing identities' (Merchant and Carrington, 2009: 63). In his seminal study on children as writers, Graves (1983) argues that the desire to write plays an important part in constructing identity, and it is crucial that each child is able to develop their individual voice through creating their own texts. Research in UK classrooms by Grainger et al (2005) shows that children benefit from opportunities to author texts that emerge from their particular interests and draw on cultural connections. For bilingual children, producing writing in home languages as well as English can give a significant boost to literacy development, as Cummins (2006) demonstrates in his discussion of 'identity texts' such as autobiographical story books made by pupils in Canadian primary schools. However, it is difficult for children to engage in dual-language writing if they are unfamiliar with their home language script. Transliteration provides a possible way forward, enabling them to express their ideas with relative fluency and ease.

\section{The study}


The work to be discussed in this paper was part of an action research project with children and teachers in Tower Hamlets, London (Kenner et al, 2008). Like many pupils in this area of East London, the children were from second and third generation British Bangladeshi backgrounds. They attended community-run after-school Bengali classes, but English was generally the only language used in their primary schools. Their teachers were unfamiliar with children's skills in Bengali and unsure as to whether and how these might contribute to their learning in the mainstream curriculum.

Our research addressed the following questions:

- In what ways do children draw on linguistic and conceptual knowledge from each of their languages to accomplish bilingual learning?

- How are children's identities as learners affected by using their home language as well as English in the classroom?

- How can bilingual and monolingual educators help children to develop bilingual learning strategies?

We worked with two groups of children in each of the two primary schools: four children aged seven and five children aged nine in School A, and four children aged seven and four children aged eleven in School B. Our team of four researchers included two fluent Bengali/English bilinguals who also knew Sylheti, originally from Bangladesh and now living in East London. This facilitated a number of key aspects of the study, including overall understanding of the linguistic and cultural context, access to community classes, insight into children's language use, comprehensive data collection and an in-depth interpretation of the findings.

First, we observed the children in their community classes. Then we worked with their primary teachers to plan bilingual tasks in literacy and numeracy for each group that were relevant to the mainstream curriculum and also linked with community class learning. The children were video- and audio-recorded as they carried out each task, and then asked to comment on how they had used their languages for learning, watching themselves on video where possible in order to aid recall. The data was discussed with community and mainstream teachers at an end-of-term seminar. Based on the ideas arising from that seminar, a new cycle of activities was planned and carried out with primary teachers in the second term.

\section{The transliteration process}

When the study began, it rapidly became clear that most of the children were not yet confident in reading or writing Bengali script. For example, in the group of four eleven-year-olds at School B, Suraiya was the only one who could read out a Bengali poem and who incorporated some Bengali words into her description of a design she had produced for a Bangladeshi-style quilt. In the group of nine-year-olds at School A, Shawon was more confident and could write the names of all his cousins in Bengali, and most of the words in a shopping list. His classmate Nayim also included a few words in Bengali script when writing in English about how his favourite football team Arsenal won the FA Cup. Other children were less confident and knowledgeable. However, several children spontaneously included some transliterated 
words within their English writing, as when Shawon wrote 'I went to my dada's bari'('my grandfather's house'). Seven-year-old Nusrat mentioned that she used this kind of writing secretly in her Bengali class, to help her remember the words.

The research team therefore adopted transliteration as a practical strategy, so that children had an additional aid to reading Bengali texts and a means of producing their own writing. After initial surprise, children responded well to this approach, for example when they encountered transliterated texts created for the bilingual activities, such as maths problems written in transliterated Sylheti. They also quickly adapted to writing in transliteration, making use of English sound-symbol relationships and translating between these and the Sylheti or Bengali sound system.

The following episode shows how the group of eleven-year-olds at School B approached the task of transliteration for the first time in the project. Having shown the group a transliterated version of a Bengali poem, their teacher asked them to write questions for their parents in Bangla, saying 'you can also write Bangla the way we do, using English letters - what do you think?' When the group was left alone to do the writing, the children clarified the concept of transliteration:

'Do we have to write in English and in Bangla?'

'No, we have to write in Bangla, but we have to write in English letters and in Bangla'

'I don't get it'

'Like this - it's easy - ai ai chad mama (reading out the title of the transliterated poem) ....it's written so that you can read it if you're English'

The children developed their transliteration skills quickly, but some sounds in Bangla are difficult to capture through English letters, such as the voiceless velar fricative $/ \mathrm{x} /$ in Sylheti. This led to some discussion as they sounded out words, trying to find the best English counterpart.

'Khene....khene....'

'How do you spell khene?'

'Just sound it out and....'

'Just write kene, OK'

Some children decided on ' $k$ ', whilst others used ' $k$ '. They also realised from the example of the transliterated poem that there is no standard spelling in transliteration:

'They didn’t spell it right a lot and it doesn’t matter' 'OK'

As they composed their questions, they began to read them out with an English accent, laughing as they did so. This language play showed their awareness that English script could not fully represent Bangla, so transliteration would produce an anglicised version if read out by a non-Bangla speaker. They also seemed to be exploring vowel sounds that lie between the English /a/ and /e/, for example:

\section{'Lagei'}


'I wrote laga' (laughter)

'It's A'

'It's E, it's E'

The children seemed to positively enjoy transliteration. After they had finished the question-writing task and several others connected with the poem, their teacher asked them 'What did you like about today?' Their first response was:

'We liked writing it in English but saying it in Bangla'

'It's a Bangla word but it's in English'

The children's comments indicated that they found this hybridity - or we could call it 'plasticity' - of spoken and written languages to be an attractive feature. Rather than wishing to keep their different languages separate, they highlighted the bridging capacities of transliteration.

\section{The Lion and the Mouse}

We shall now move to a detailed discussion of the different ways in which transliteration can act as a bridge, through an activity which took place with the group of four seven-year-olds in School A. The text selected for this activity was the Bengali version of the folk tale 'The Lion and the Mouse', from a book produced in Bangladesh to teach children Bengali script. The story is as follows: a lion is asleep in a cave, and a mouse approaches and sits on his nose. The lion catches the mouse but the mouse talks to him and convinces the lion to let him go. Later the lion gets caught in a hunters' net, and the mouse eats through the net to release him. So at the end of the story the lion and the mouse become friends, and the moral is 'you can help even if you are small'.

The same book is used in community language classes in London to teach second and third generation British Bangladeshi children, but for them it is much more difficult to access the text because, as mentioned earlier, they have only a few hours a week to learn Bengali literacy, and English is the dominant language. One aspect of our study was to investigate how a text like this could be used to support learning in both Bengali and English.

We therefore brought the text from community class into the mainstream school. The primary teacher wanted to find a way that he, the children and their parents could communicate ideas about the story to each other. He decided to adopt a 'Story Sharing' approach, sending a picture-only version home to parents with the words blanked out, accompanied by a letter asking them to write their own captions for each picture together with their children. Above the pictures, the title of the story was transliterated into both Standard Bengali and Sylheti, in order to encourage parents and children to write in transliteration if they wished:

shingho ow idhur ('the lion and the mouse' in Standard Bengali, transliterated) shingho ow oondur (('the lion and the mouse' in Sylheti, transliterated) 
To facilitate the discussion with parents, the teacher asked the four children to prepare questions in transliterated Bangla to take home. They received additional help from Hanna (the nine-year-old sister of Jameela, one of the children in the group), who was designated by the teacher to lead the task. To explain what transliteration meant, the teacher first showed the example of the story titles, and said 'this is called transliterating', encouraging the children to read the words out. The teacher then asked them how they would transliterate the Sylheti word shesh ('finish') and they spelled it out 'S-H-E-S-H'. His final instruction before they began their task was 'use Bangla, but use English letters to sound it out'.

The children discussed the story and each wrote four questions in transliteration for their parents. The teacher had encouraged them to speak in Bangla, and communicating bilingually proved effective as children freely code-switched between Bangla and English to help them accomplish their task.

A few days later, they brought their parents' answers back to school, along with the stories written at home. There were a variety of different responses, from parents answering the questions and writing the story in Bengali script, to children themselves writing down the answers and the story in transliterated Sylheti, and various combinations in between. One particular version of the story, written by nine-year-old Hanna in consultation with her mother and seven-year-old sister Jameela, proved particularly apt for the children to work with further in school since it was in transliterated Sylheti with familiar vocabulary and sentence structure. The teacher gave the children their second task: to translate this version into English. Having worked out the translation and written it down by themselves, they then discussed it with the teacher.

The Lion and Mouse story was also available in English in the primary school in a Big Book version (a larger-size text used by teachers for reading to whole-class groups), and indeed the children remembered having the story read to them at school a couple of years earlier. In the third stage of the activities using transliteration, the children were given the task of writing their own version of the story in Bangla, using only the pictures in the Big Book as a point of reference, since the teacher had covered up the writing. The children worked out the story collaboratively and wrote it down by themselves in transliteration, taking it in turns to write in the Big Book (on the pieces of paper covering the original wording) and meanwhile keeping up with writing the story in Bangla in their own exercise books, where they also provided an English translation. Finally, the group acted out their story for the rest of their class by using finger puppets, with one of the boys, Junel, reading the Bangla version aloud.

We shall now consider how, during these activities, transliteration operated as a communicative bridge between children, parents and teachers; as a conceptual bridge encouraging children to consider word meanings and linguistic structure; as a bridge from spoken Sylheti to written Standard Bengali; and as a bridge to bilingual learner identities.

\section{A communicative bridge}


Transliteration helped to create a communicative bridge between children and their bilingual parents as well as children and the monolingual teacher. In both cases the children and adults would otherwise have been divided by script when engaging with written text.

The seven-year-olds would not have been able to write questions for their parents in Bengali script. However, transliteration enabled them to present their ideas and set up a dialogue with their parents in Bangla. The answers and the story could then be written by parents or children in a variety of ways; some of the responses brought back were in transliterated Sylheti, whilst others were in Bengali script, and some included English words as well. Here we focus on Miqdad's questions and his father's answers, as an example of how transliteration fostered intergenerational communication around the story.

The children were aware that Bangla played an important role in the lives of their families, and Miqdad's first question gave his parents the opportunity to state why this was the case:

Cene Bangla beshi important?

('Why is Bangla very important?')

Although there are several Bengali equivalents for 'important', Miqdad was accustomed to hearing the English word used within spoken Bangla as a code-mixed expression. Code mixing, where linguistic elements are transferred from one language to another within the same sentence (Wardhaugh, 1992), and code switching, where the move between languages takes place at the clausal or sentential level (Gumperz, 1982), are very common amongst stable bilingual and multilingual communities in the UK, as shown by research such as that of Al-Azami (2005) with British Bangladeshis in Manchester.

Miqdad's father wrote his answer to this question in Bengali script:

'Bangla is a part of our culture. We, the Bangladeshis, speak in Bangla and write. That's why Bangla is very important.'

The words 'culture' and 'important' were written in English. These are words that Miqdad was used to hearing in English only. By representing 'culture' and 'important' in English script, the father was also linking with his son's transliterated writing. Although Miqdad would not have been able to read most of this answer, father and son would have discussed it in spoken Bangla and Miqdad retained some access to the written answer through the inclusion of these particular words.

Miqdad's second question was:

Shingho caly goomy cene?

('Why does the lion keep sleeping?')

His father's answer, again mostly in Bengali script, was:

'The lion looks very tired, that's why he keeps sleeping.' 
In this case he made a connection with Miqdad's question by writing the key word shingho (lion) in transliteration.

Miqdad's third question was:

Shingho oondur re cay no cene?

('Why does the lion not eat the mouse?')

The answer from his father in Bengali script was quite complex, giving an overview of the story:

'When the lion was caught in a hunter's net, the mouse cut the net and helped the lion get out. And that's why the lion didn't eat the mouse.'

Here again, the key words shingho and oondur ('lion' and 'mouse') are in transliteration.

The final question was:

Ce shingho re dorse?

('Who caught the lion?')

And the answer was:

'Some hunters caught the lion.'

So we can see how Miqdad's questions built on the story in interesting ways, and enabled a discussion with his father. The transliterated questions provided a stimulus for story sharing and more extended understanding. The parent conformed to the linguistic competence of the child and used code mixing as well as transliteration, creating a communicative bridge between two generations with different dominant languages and scripts.

A similar bridge was created between the children and their monolingual teacher. The teacher involved in the Lion and Mouse activity commented that, for him, transliteration was the most important thing he had learned from the research. Previously, he had only known a couple of words in spoken Bangla. Transliteration made it possible for him to engage with Bangla through writing and discuss the meaning and structure of the language with the children. The following interaction, for example, took place when teacher and children were studying Hanna's transliterated version of the story and the children's translation written in English.

Jameela: (reads out) 'The lion is sleeping in the cave'

Teacher: (noticing that there are fewer words in the Bangla transliteration)'Where's the word 'the'?

Miqdad: No 'the'!

Teacher: Why didn't you just say 'lion is sleeping'?

Amal: Because there is 'the' in there but when you say it in English you add the 'the' 
Teacher: So in Bengali there's no word for 'the lion', it's just 'lion'?

Miqdad: I don't know

Amal: If a person was talking to another person and the person was saying a word, and said it without 'the', erm the other person would know because...

Teacher: So you put in the word 'the' because it makes more sense.

Transliteration enabled the teacher to read the Bangla version of the story and compare it with the English translation. It facilitated the above discussion, which showed the children's awareness of a particular grammatical difference between the two languages with regard to the use of the definite article. The teacher's request for clarification led Amal to explain that speakers of Bangla would not find the omission of 'the' problematic because of their shared communicative understanding. By her statement 'there is 'the' in there', she meant that the word 'lion' in Bangla could be taken to include the definite article in this context, whereas in English it would need to be specified.

Later, the teacher asked the children to comment on word order in Bengali and English, and on why they had added an extra word in the English version. The discussion focused on the following sentence:

Tow oondure shinghor loge mattse (transliterated Bangla)

Then mouse lion's with talking (literal translation)

Next the mouse started to talk to the lion (the children's translation)

Teacher: So do you see how we've changed it, because if we just translated this it says 'next lion mouse with talk'.

Miqdad: It won't make sense.

Teacher: Where's the word 'started'?

Amal: He put 'started' in.

Teacher: Why?

Jameela: It makes more sense.

Teacher: cos if I said to you 'next lion mouse with talk...' (children smile) you'd look at me going...

Miqdad: Wha-at? (exaggerated intonation)

Teacher: it wouldn't make sense - so you've changed it to make it make sense in English which is good

Here we see that teacher and children constructed a shared understanding of how translation works, made possible because the teacher could access Bangla through transliteration. Two issues arose: that word order was different in the two languages, and that a literal translation might not be sufficient, so an addition might need to be made in order to fully express the meaning. Such discussions made the teacher aware of the children's linguistic knowledge, which had previously been hidden to him.

\section{A conceptual bridge}

During the Lion and Mouse activities, transliteration enabled the children to engage with concepts, and to demonstrate and extend their metalinguistic knowledge, in ways that it would have been difficult to do through speech alone. 
Firstly, the process of transliteration involved the children in a deeper consideration of sound-symbol relationships than would have arisen from writing only in English. When they used transliteration for the first time, they slowly sounded out the Bangla words and talked together about how to represent Bangla sounds, transferring their phonetic knowledge from English, like the eleven-year-olds whose approach to transliteration was discussed above. By the time they were writing their own collaborative story in Bangla, they were transliterating more rapidly. However, they sometimes wrote different versions of the same Bangla phrase, showing that that they had taken individual decisions on the most appropriate way to represent Bangla using resources available from English. A striking example comes in the phrase 'They said NO!' (the reply from the giraffe, the snake and the elephant when the lion asked for help, in the children's version of the Big Book story).

$$
\text { They said “NO!” }
$$

$\begin{array}{ll}\text { Jameela } & \text { thara khoson "Na!" } \\ \text { Junel } & \text { Tara coisoin "NA!" } \\ \text { Miqdad } & \text { tara khoisoin "NA"! } \\ \text { Amal } & \text { tara koyson "Na”! }\end{array}$

All these are acceptable versions because they evoke the Bangla sounds. Each version gives a window onto a particular child's thinking. For example, two children chose to represent the voiceless velar fricative / $\mathrm{x}$ / in Sylheti with ' $\mathrm{kh}$ ', whilst the others decided on a ' $k$ ' or a ' $c$ '. The ' $t$ ' in 'tara' presents a challenge because it is unaspirated in Bangla compared to the aspirated sound in English, and therefore comes somewhere in between a / $t /$ and $a / d /$ in English letters. Jameela chose to give the ' $t$ ' more emphasis by writing 'th', whilst the others did not (perhaps because 'th' evokes a different sound in English). Transliteration thus required the children to explicitly consider subtle differences between sounds in the two languages, and to develop their skills in using a phonics-based approach.

Producing a written version of Bangla words also raised grammatical issues, such as that of suffixes, which are commonly used in Bangla. The children's awareness of suffixes was shown by the way in which they hybridised Bangla and English within the same word. When writing during the Lion and the Mouse tasks, they put an English plural ending '-s' on a Bangla word to create 'bondos' ('friends'), and attached a Bangla suffix '-or' to an English word to produce 'netor' ('in the net'). This fluent use of hybridisation is typical of second and third generation British Bangladeshi children's talk in Tower Hamlets, as shown by Murshad's research in a nearby primary school playground (Murshad, 2002). In talk, the grammatical processing is done instantaneously. However, the demands of writing can provoke further reflection. The children wrote suffixes attached to the noun, showing that they considered them an integral part of the word. However, when writing the phrase 'giraff ar hati' ('giraffe and elephant'), a discussion arose as to whether it should be written as 'giraffar' or 'giraff ar'. Miqdad sounded it out as 'giraff ar', emphasising the separation between the two words and thus making it clear that 'ar' ('and') was not a suffix. All the children then wrote down 'giraff ar' as two separate words.

A particularly complex grammatical question arose when the children were trying to decide how to translate the lion's call of 'Help!' (when caught in the hunters' net). 
Whereas in English the word 'help' is both noun and verb, its Bengali counterpart shahajjo is only a noun, so it has to be combined with the action word khorbe (ie 'give help'). Miqdad said 'khorbe' and began spelling out this word, while Jameela suggested a different solution:

'I'm gonna do shad, shad, dibay...shad dibaini... Not khorbe, you write help, it's shad, shad'

Jameela chose the Sylheti version of 'help', which is shad. She also realised that shad could not stand alone and looked for an action word to go with it, deciding on dibaini ('give me'). Miqdad approved of Jameela's approach and incorporated her wording into the story.

The process of translation tends to generate discussion about word meanings, since there are sometimes no literal equivalents in the other language. Being able to write the words down through transliteration gave the children more scope to think about semantic differences between Bangla and English. This occurred, for example, when children were discussing how to translate the word 'caught' from English to Bangla. For the phrase 'the lion caught the mouse', they knew that dorse was the correct word, but they realised that dorse was not appropriate when they wanted to state that the lion was caught in a net. 'Caught' covered both meanings in English, whereas different words would be used in Bangla. The meaning of 'caught' in the second phrase would be 'trapped', and is passive rather than active. Although the children did not explicitly articulate these differences, they were not satisfied with dorse and came to ask the researcher how to say 'caught' in Bangla. They then decided to take up the creative solution offered by nine-year-old Hanna's original version: shinghor oophre gal forrse ('the net fell on the lion'). Rather than taking the English word 'caught' for granted, the children therefore had to delve more deeply into the potential meanings of the word, leading to what Moore (2002) has called 'enriched conceptualisation'.

\section{A bridge from oral to written}

As discussed earlier, most Bangladeshi children in Tower Hamlets come from a Sylheti background and thus their language no longer has a written version. If they do know some standard Bengali and wish to express themselves in writing, the script still presents a challenge. Bengali has a syllabic writing system or 'abugida' where all consonants have an inherent vowel, which has two different possible pronunciations depending on the context. Vowels can function as independent letters, or can be represented by a variety of diacritical marks that are written above, below, before or after the consonant they belong to. Special conjoined letters are used to represent consonant clusters. Given these complexities, our research indicated that transliteration can be an intermediary way for second and third generation children with a Sylheti background to first know how to transfer their spoken knowledge into writing, by using the Roman script with which they are more familiar, and then move on to learning the Bengali script itself.

Through using transliteration for the Lion and Mouse tasks, and being given freedom to use Bangla (ie to use Sylheti and/or to code switch) rather than being confined to Standard Bengali, the children were able to codify their oral expressions for the first time. They not only composed questions for their parents, but also their own story. 
During the activities, we found awareness by the children of differences between Sylheti and Standard Bengali. For example, when the teacher asked the children to do transliteration for the first time, Hanna, who was leading the task, said:

'OK I'll start. Ekhdin ('one day') yeah, I'll do it in Sylheti how we speak. Ekhdin shingho gumayse ar ehm oondur ayse' ('one day the lion was sleeping and umm the mouse came').

Later, Hanna showed that she was also able to produce part of the story in Standard Bengali:

'This is easy, say it in Bengali ekhdin zokhon shingho baire gese ehm tare

khita dorilaise' ('one day when the lion went out something caught him yeh'). She switched to Sylheti at the end of the sentence - khita dorolaise ('something caught him') - probably because she was not sure of the vocabulary in Standard Bengali at that point.

Whilst the children found Sylheti much easier to use than Standard Bengali, they showed awareness of some differences between the two varieties when writing. When the seven-year-olds were composing their Lion and Mouse story collectively, Jameela suggested writing Hara khoson 'Na!' (they said 'No!'). Hara is the Sylheti term which children would only use when speaking, but what Jameela actually wrote down was thara, the Standard Bengali form, and as shown earlier, all four children used tara or thara when writing this phrase in their exercise books. So as well as using transliteration as an interlingual bridge to aid translation activities between Bangla and English, they could move intralingually between varieties of Bengali.

We also saw indications that transliteration, by providing an intermediate form of codification, could help children to write in Bengali script. For example, Tasnim, one of the Year 4 children at School A, found it very difficult to write in Bengali during a task at her after-school Bengali class. She was then asked to use transliteration first while writing a story in Bangla. Once she found that she could transfer her oral skills into writing, she became more confident and later used the transliteration to sound out the words and work out which letters she should use in Bengali script. Although she initially predicted she would only be able to write one or two words in the script, she actually accomplished twelve words relatively quickly because this approach proved so fruitful.

\section{A bridge to new learner identities}

Transliteration gave children the chance to be authors, and they proved to be motivated and enthusiastic writers in Bangla. They quickly grasped the concept of transliteration and its potential. When they were about to begin their collective version of 'The Lion and the Mouse' in Bangla, one of the researchers asked what task they had been given and the children replied: 'tras - trasliterate the Lion and the Mouse story...in Bangla, writing in English, but Bangla words'. They proceeded to compose and write rapidly, with Miqdad and Junel reminding the group to speak in Bangla (Bangla mato). They took it in turns to write in the Big Book, each scribing the caption that had been collectively discussed for the picture on that particular page. Their individual exercise books were placed on another table nearby, so children were running to and fro to check what had been written in the Big Book and write it down for themselves. They became very excited as they suggested adding speech marks, 
question marks and exclamation marks (also used in Bengali) at appropriate moments, and writing 'NA!' ('NO!') in capital letters when the animals refused to help free the lion from the net. At one point, they went through the Big Book checking that they had put a Bengali full stop or dari (a short vertical line) at the end of each sentence. Their concern with accuracy suggests that they did not regard transliteration as a makeshift form of writing, but were proud of their finished story.

Transliteration also enabled the children to use their full linguistic repertoire, not only in Bangla but also in Arabic. They wrote the Arabic term jazakallah, which means 'thanks', to show the lion's expression of gratitude to the mouse when it helped the lion get out of the hunter's net. The Bengali word for thanks is dhonnobad, but the word is rarely used even among native speakers, for whom the English word 'thanks' or 'thank you' is more common. The Arabic word for 'thanks' is shukran and the word jazakallah is an Islamic way of thanking, which means 'May God reward you'. This term is often used in spoken interaction amongst Muslims in Tower Hamlets and the children thus transferred their oral culture of showing thankfulness into their own story writing.

For these second and third generation children, transliteration was a key that opened a pathway to literacy in Bangla. Their reactions were very positive. When one of the researchers asked how they felt about transliteration, they said:

Junel: It's exciting - it's something that I learned

Miqdad: Cool. Different. We never done it before.

Although this approach to writing was new to them, it was easily accomplished once they were invited to use their skills. Collectively, the children said, 'It's easy - we just think and we know how to write it'. When asked whether it helped them to write Bangla in this way, the children replied that it did, 'Because then we know what it says. If we write in Bangla (ie Bengali script) we don't know what it says but if we write like this....' These comments show how transliteration is a bridge for children to put their thoughts into words, and enhances their self-esteem as learners who have the knowledge to express themselves in written Bangla.

\section{Conclusion}

The findings of this project indicate that transliteration has considerable potential to aid learning. Particularly where a language has no written form or where children are unfamiliar with the script, transliteration transforms speech into writing, which can be a first step towards learning the script itself and also creates a communicative bridge between children and parents. Furthermore, once words are written down it is much easier to discuss and analyse their content, so writing in transliteration can help children in their thinking. Reflection on meanings in different languages can lead to enriched conceptualisation, whilst reflection on different language structures can lead to enhanced metalinguistic knowledge. Transliteration helps mainstream teachers who have little knowledge of children's heritage language to develop an understanding of how the language works and recognise its importance in children's cognitive development. Finally, transliteration is liberating and empowering for bilingual 
children who would otherwise be limited to expressing themselves in English in their writing.

Our research suggests that teachers in community and mainstream contexts could use transliteration as a productive tool for learning, making it possible for children to draw on the full range of their linguistic resources and encouraging self-expression, translation of ideas and discussion of linguistic structure. At School A, for example, the Bengali teacher has built transliteration into his teaching, using it alongside the equivalent words and phrases written in Bengali script. This approach provides a means of children recording and remembering their oral learning, and is proving a helpful transition to learning the script. In further work at School A, class teachers have continued to explore the uses of transliteration in cross-curricular multilingual activities.

Given the advantages we have found through our research - for children's learning, and for their communication with parents and with teachers - we would suggest that transliteration is an effective bridge for second and third generation children who are working with different scripts, enabling them to maximise the cognitive and linguistic benefits of bilingualism.

\section{Acknowledgements}

The project Developing Bilingual Learning Strategies in Mainstream and Community Contexts was funded by the Economic and Social Research Council (Award R000221528).

We would like to thank all the children, teachers and families who participated in the study.

\section{References}

Al-Azami, A.S. (2005). Language Maintenance and Shift among the Bangladeshis in Manchester. Edge Hill, Lancashire: ICDES, Edge Hill University.

Anderson, J., Kenner, C. and Gregory, E. (2008) The National Languages Strategy in the UK: are minority languages still on the margins? In C. Hélot and A. De Mejía (eds) Forging Multilingual Spaces: Integrating Perspectives on Majority and Minority Bilingual Education. Clevedon: Multilingual Matters.

Baker, C. (2006) Foundations of Bilingual Education and Bilingualism. Clevedon: Multilingual Matters.

Beacco, J-C. and Byram, M. (2003) From Linguistic Diversity to Plurilingual Education: Guide for the Development of Language Policies in Europe. Strasbourg: Council of Europe.

Blackledge, A. (2000) Literacy, Power and Social Justice. Stoke-on-Trent: Trentham Books. 
Blackledge, A. (2004) Constructions of identity in political discourse in multilingual Britain. In A. Pavlenko and A. Blackledge (eds) Negotiation of Identities in Multilingual Contexts. Clevedon: Multilingual Matters.

Chalmers, R. (1996). Learning Sylheti. London: Centre for Bangladeshi Studies.

Conteh, J., Martin, P. and Helavaara Robertson, L. (2007) Multilingual learning stories from schools and communities in Britain: issues and debates. In J. Conteh, P. Martin and L. Helavaara Robertson (eds) Multilingual Learning: Stories from Schools and Communities in Britain. Stoke-on-Trent: Trentham Books.

Council of Europe (1992) European Charter for Regional or Minority Languages. http://conventions.coe.int/treaty/en/Treaties/Word/148.doc (Accessed September 2009)

Cummins, J. (2006) Identity texts: the imaginative construction of self through multiliteracies pedagogy. In O. García, T. Skutnabb-Kangas and M. Torres-Guzmán (eds) Imagining Multilingual Schools: Languages in Education and Glocalization. Clevedon, Avon: Multilingual Matters.

DES (Department of Education and Science) (1985) Education for All: The Swann Report. London: HMSO.

DfES (Department for Education and Skills) (2002) Languages for All: Languages for Life. A Strategy for England. Annesley, Notts: DfES.

Edwards, V., Monaghan, F. and Knight, J. (2000) Books, pictures and conversations: using bilingual multimedia storybooks to develop language awareness. Language Awareness 9 (3), 135-146.

Eilers, R., Pearson, B. and Cobo-Lewis, A. (2006) Social factors in bilingual development: the Miami experience. In P. McCardle and E. Hoff (eds) Childhood Bilingualism: Research on Infancy Through School Age (pp. 68-90). Clevedon: Multilingual Matters.

Fitzpatrick, F. (1987) The Open Door. Clevedon: Multilingual Matters.

Fishman, J. (1991) Reversing Language Shift. Clevedon: Multilingual Matters.

Goody, J. and Watt, I. (1968) The consequences of literacy. In J. Goody (ed) Literacy in Traditional Societies. Cambridge: Cambridge University Press.

Grainger, T., Goouch, K. and Lambirth, A. (2005) Creativity and Writing: Developing Voice and Verve in the Classroom. London: Routledge.

Graves, D. (1983) Teachers and Children at Work. Portsmouth, NH: Heinemann.

Gregory, E. and Williams, A. (2000) City Literacies: Learning to Read Across Generations and Cultures. London, Routledge. 
Gumperz, J. (1982) Discourse Strategies. Cambridge: Cambridge University Press.

Heller, M. (1995) Language choice, social institutions, and symbolic domination. Language in Society 24, 373-405.

Islam, S. (ed) (2003). Banglapedia: The National Encyclopedia of Bangladesh. Dhaka, Bangladesh: Asiatic Society of Bangladesh.

Jessel, J., Arju, T., Gregory, E., Kenner, C. and Ruby, M. (2004) Children and their grandparents at home: a mutually supportive context for learning and linguistic development. English Quarterly 36 (4), 16-23.

Kenner, C., Gregory, E., Ruby, M. and Al-Azami, S. (2008) Bilingual learning for second and third generation children. Language, Culture and Curriculum 21 (2), 120137.

Lau, S-F and Wang, V. (1993) Chinese personal names and titles: issues in cataloging and retrieval. In A. Kent (ed) Encyclopedia of Library and Information Science Vol. 52. Boca Raton, FL: CRC Press.

Li Wei (1994) Three Generations, Two Languages, One Family: Language Choice and Language Shift in a Chinese Community in Britain. Clevedon: Multilingual Matters.

Merchant, G. and Carrington, V. (2009) Literacy and identity. Literacy 43 (2), 63-64.

Moore, D. (2002) Case study: code-switching and learning in the classroom. International Journal of Bilingual Education and Bilingualism 5 (5), 279-293.

Murshad, A. (2002) Tools for talking: the purposeful and inventive use of languages by bilingual children in primary classrooms. Reading, Literacy and Language 36 (3), 106-112.

Olson, D. (1977) From utterance to text: the bias of language in speech and writing. Harvard Educational Review 47 (3), 257-281.

Ong, W. (1982) Orality and Literacy. London: Routledge.

Onwuemene, M. (1999) Nigerian writers' endeavors toward a national literary language. PMLA 114 (5), 1055-1066.

QCA (Qualifications and Curriculum Authority) (2000) Curriculum Guidance for the Foundation Stage. London: QCA.

Robertson, L.H. (2002) Parallel literacy classes and hidden strengths: learning to read in English, Urdu and classical Arabic. Reading, Literacy and Language 36 (3), 119126.

Sneddon, R. (2000) Language and literacy: children's experiences in multilingual environments. International Journal of Bilingual Education and Bilingualism 3 (4), 
pp. 265-282.

Sneddon, R. (2008) Magda and Albana: learning to read with dual language books. Language and Education 22 (2), 137-154.

Street, B. (1984) Literacy in Theory and Practice. Cambridge: Cambridge University Press.

TDA (Training and Development Agency for Schools) (2008) Results of the Newly Qualified Teacher Survey 2008. London: TDA.

Tower Hamlets Community Languages Service (2006). Mother Tongue Provision and Educational Achievement. London: Tower Hamlets Local Authority.

Vygotsky, L. (1978) Mind and Society. Cambridge, Mass: Harvard University Press.

Wardhaugh, R. (1992) An Introduction to Sociolinguistics. Oxford: Blackwell. 